\title{
Reaction norm of fertility traits adjusted for protein and fat production level across lactations in Holstein cattle
}

\author{
A. Menendez-Buxadera, ${ }^{*}+$ M. J. Carabaño, ${ }^{1}$ O. Gonzalez-Recio,‡ R. I. Cue,§ E. Ugarte,\# and R. Alenda* \\ *Departamento de Producción Animal, Escuela Técnica Superior de Ingenieros Agrónomos, Universidad Politécnica, Madrid 28040, Spain \\ †Universidad de Córdoba, Departamento de Genética, Grupo Meragen, Rabanales, Cordoba 14071, Spain \\ ‡Departamento de Mejora Genética Animal, Instituto Nacional de Investigación y Tecnología Agraria y Alimentaria (INIA), Madrid 28040, Spain \\ §Department of Animal Science, McGill University, Montreal, QC, H9X 3V9, Canada \\ \#Departamento de Producción Animal, Neiker, 01080 Vitoria-Gasteiz, Spain
}

\section{ABSTRACT}

A total of 304,001 artificial insemination outcomes in up to 7 lactations from 142,389 Holstein cows, daughters of 5,349 sires and 101,433 dams, calving between January 1995 and December 2007 in 1,347 herds were studied by a reaction norm model. The (co)variance components for days to first service (DFS), days open, nonreturn rate in the first service (NRFS), and number of services per conception were estimated by 6 models: 3 Legendre polynomial degrees for the genetic effects and adjustment or not for the level of fat plus protein (FP) production recorded at day closest to DFS. For all traits and type of FP adjustment, a second degree polynomial showed the best fit. The use of the adjusted FP model did not increase the level of genetic (co)variance components except for DFS. The heritability for each of the traits was low in general $(0.03-0.10)$ and increased from the first to fourth calving; nevertheless, very important variability was found for the estimated breeding value (EBV) of the sires. The genetic correlations $\left(\mathrm{r}_{\mathrm{g}}\right)$ were close to unity between adjacent calvings, but decreased for most distant parities, ranging from $r_{\mathrm{g}}=0.36$ (for DFS) to $\mathrm{r}_{\mathrm{g}}=0.63$ (for NRFS), confirming the existence of heterogeneous genetic (co)variance components and EBV across lactations. The results of the eigen decomposition of $r_{g}$ shows that the first eigenvalue explained between 82 to $92 \%$ and the second between 8 to $14 \%$ of the genetic variance for all traits; therefore, a deformation of the overall mean trajectory for reproductive performance across the trajectory of the different calving could be expected if selection favored these eigenfunctions. The results of EBV for the 50 best sires showed a substantial reranking and variation in the shape of response across lactations. The more important aspect to highlight, however, is the difference between the EBV of the same sires in

Received October 11, 2012.

Accepted March 22, 2013.

${ }^{1}$ Corresponding author: mjc@inia.es different calvings, a characteristic known as plasticity, which is particularly important for DFS and NRFS. This component of fertility adds another dimension to selection for fertility that can be used to change the negative genetic progress of reproductive performance presented in this population of Holstein cows. The use of a reaction norm model should allow producers to obtain more robust cows for maintenance of fertility levels along the whole productive life of the cows.

Key words: Holstein reproduction trait, genetic parameter, reaction norm model, plasticity

\section{INTRODUCTION}

Maintaining profitability on dairy farms largely relies on attaining high levels of production per cow (VanRaden, 2003; González-Recio et al., 2004; Miglior et al., 2005). Therefore, production (milk, fat, protein, and components paid for) is the trait that receives the largest selection pressure in most dairy cattle populations (Shook, 2006; Interbull, 2012). However, high-yielding cows are prone to show a negative energy balance around the peak of production, which interferes with their ability to become pregnant, given that the time of first insemination and the negative energy balance period coincide (Veerkamp et al., 2008). Therefore, future sustainability of intensive production systems for dairy cattle will largely rely on the ability to select animals that can cope with increasing levels of milk production while avoiding undesired culling for reproductive failure. Given that the production level increases from the first to the following lactations, energy balance of cows in second and subsequent lactations can increasingly deteriorate if the cow is not able to recover its body condition before the next calving. Up to now, fertility of lactating cows has been evaluated using a variety of traits (Jorjani, 2007) and, generally, the models used consider reproductive traits along successive parities as repeated measures of the same trait. However, the use of this approach has some drawbacks. First, genetic evaluations may be biased if the underlying assump- 
tions of constant genetic (co)variances, breeding values across lactations, and unity correlations between lactations do not hold. Second, and more importantly in the context of selection for robustness in high-yielding cows, eventual differences in the genetic ability to maintain initial reproductive performance along parities cannot be detected.

The analysis of traits measured at different time points in the animal's productive life has been undertaken from different perspectives. First, as function valued traits characters (Pletcher and Geyer, 1999), that is, traits that change as a function of some independent and continuous variable (e.g., a time scale measured as parity number), using covariance functions (Kirkpatrick et al., 1990), or, equivalently, random regression models (RRM; Schaeffer and Dekkers, 1994). Alternatively, observed phenotypes taken in the same individual along time can be viewed as a set of responses to environmental variation at different time points (e.g., reproductive response to changes in production level and associated body condition along successive lactations) in the context of reaction norm models (Gomulkiewicz and Kirkpatrick, 1992). Reaction norm models can also be viewed as a special case of RRM (Kolmodin et al., 2002). Fertility traits fall into the function valued traits category or can also be viewed as reactions to changing conditions along parities and could be properly analyzed by using RRM (Schaeffer, 2004). Reaction norm models to study the sensitivity of production traits to different environments or plasticity of production have been previously used in several studies (de Jong, 1995; Kolmodin et al., 2002; Calus and Veerkamp, 2003). However, bibliographical references about this type of analysis for fertility traits across parities are very scarce.

The objective of this study was to estimate genetic (co)variance components and breeding values for changes in reproductive performance across parities. The reaction norm models used accounted or not for fat plus protein production at the closest day to first service. This type of model provides a way of measuring both the level and persistency of reproductive performance, which might help in selecting more robust and profitable cows.

\section{MATERIALS AND METHODS}

\section{Data}

Records from the official milk and reproductive recording program in the Basque country, Girona and Navarre in Spain, were used in this study. The overall reproductive file contained 316,565 AI records from up to 7 parities of Holstein cows calving between Janu- ary 1995 and December 2007 in 1,347 herds. Test-day yields closest to the insemination date for the cows with reproductive information were extracted from an overall file with $3,201,353$ milk, fat, and protein test-day records collected on a monthly basis. A maximum absolute distance of $31 \mathrm{~d}$ between the day of first service and the closest (preceding or subsequent) milk test day was required. After editing and merging both data files, 304,001 AI outcomes in up to 7 lactations from 142,389 Holstein cows were included in the subsequent analyses. These cows were daughters of 5,349 sires and 101,433 dams (56,090 of these dams were themselves present in the data). The pedigree file contained a total of 223,711 individuals.

Reproductive performance was measured by 4 traits: interval (days) from calving to first service (DFS), days open (DO), nonreturn rate in the first service (NRFS), and number of services per conception (NSC). The editing process for these 4 characters followed the same restriction as in González-Recio et al. (2004). Fat plus protein yield (FP) in the test day closest to the day of first service was used to adjust for level of production.

\section{Statistical Analyses}

Single trait models for each fertility trait were used. The following general model formulation applied for all traits:

$$
\begin{aligned}
& y_{i j k l m n \tau \lambda}=\mathrm{RYS}_{i}+\sum_{r=0}^{r=2} \alpha_{r j} \Phi_{r}(\tau)+\sum_{r=0}^{r=2} \beta_{r j} \Phi_{r}(\lambda) \\
& +\sum_{r=0}^{r=0,1,2} a_{r k} \Phi_{r}(j)+p_{l}+h_{m}+e_{i j k l m n \tau \lambda},
\end{aligned}
$$

where $y_{i j k l m n \pi \lambda}$ is the fertility trait observation (DFS, DO, NRFS, NSC); $\mathrm{RYS}_{i}$ is the $i$ th combination of region, year, and season of calving $(i=1, \ldots, 114) ; \alpha_{r j}$ is the $r$ th fixed regression coefficient on months of age at calving $(\tau)$, nested to the $j$ th level of parity $(j=$ $1, \ldots, 7) ; \beta_{r j}$ is the $r$ th fixed regression coefficient on kilograms of $\mathrm{FP}(\lambda)$, nested to the $j$ th parity; $a_{r k}$ is the $r$ th random additive genetic regression coefficient on lactation number $(j)$ for animal $k(k=1, \ldots, 223,711)$; $\Phi_{r}$ is the $r$ th term of the Legendre polynomial where the time variable was alternatively age at calving $(\tau)$, FP yield $(\lambda)$, or the lactation number $(j)$; the order of fit was $r=2$ (intercept, linear, and quadratic terms) for the fixed Legendre polynomials, but $r=0,1,2$ for the random animal genetic effect, leading to 3 different models for each order of fit; $p_{l}$ is the random permanent environmental effect for cow $l(l=1, \ldots, 142,389) ; h_{m}$ is the random effect of herd $m(m=1, \ldots, 1,122)$; and $e_{i j k l m n \tau \lambda}$ is the residual term. 
The (co)variance matrices for random effects were

$$
\begin{gathered}
V(\mathbf{a})=\mathbf{G}_{o} \otimes \mathbf{A}, \\
V(\mathbf{p})=\mathbf{I}_{p} \sigma_{p}^{2}, \\
V(\mathbf{h})=\mathbf{I}_{h} \sigma_{h}^{2}, \\
V(\mathbf{e})=\mathbf{R},
\end{gathered}
$$

where $\mathbf{G}_{0}$ is the covariance matrix for random additive genetic regression coefficients (in vector $\mathbf{a}$ ); $\mathbf{A}$ is the additive relationship matrix; $\mathbf{I}_{p}$ and $\mathbf{I}_{h}$ are identity matrices for permanent environmental and herd effects, respectively; $\sigma_{p}^{2}$ and $\sigma_{h}^{2}$ are the variances of permanent environmental (in vector $\mathbf{p}$ ) and herd effects (in vector $\mathbf{h})$, respectively; $\mathbf{e}$ is the vector of residual terms; and $\mathbf{R}$ is the matrix of residual variances. Heteroscedasticity of residual effects was considered for first, second, third, fourth, and fifth and subsequent lactations.

The model described above, which included a quadratic regression on FP, adjusted FP (FPAd). Alternatively, the regression on FP was excluded from the model and the resulting model did not adjust FP (FPUnAd). Overall, 6 models for the combination of 3 polynomial degrees for the genetic effects and adjustment using FP or no adjustment were run for each fertility trait. ASReml 3.0 (Gilmour et al., 2009) was used to obtain the (co)variance components associated with the random effects and solutions for the effects included in the model.

Estimated breeding values for an animal $(i)$ at a given lactation $(j)$ were obtained by

$$
\mathrm{EBV}_{i}^{j}=\boldsymbol{\Phi}(j)^{\prime} \hat{\mathbf{a}}_{i},
$$

where $\boldsymbol{\Phi}(j)$ is a vector of Legendre polynomials coefficients evaluated at time (lactation) $j$; and $\hat{\mathbf{a}}_{i}$ is the vec- tor of estimated additive genetic values of the regression coefficients for animal $i$.

The estimated (co)variances of the additive genetic regression coefficients at time (lactation) $j$ and $j^{\prime}$ were obtained by

$$
\hat{\sigma}_{a}\left(j, j^{\prime}\right)=\boldsymbol{\Phi}(j)^{\prime} \hat{\mathbf{G}}_{O} \boldsymbol{\Phi}\left(j^{\prime}\right) .
$$

Heritability estimates at a given lactation $j$ were obtained as

$$
\hat{h}^{2}(j)=\frac{\hat{\sigma}_{a}^{2}(j)}{\hat{\sigma}_{a}^{2}(j)+\hat{\sigma}_{p}^{2}+\hat{\sigma}_{h}^{2}+\hat{\sigma}_{e j}^{2}},
$$

where $\hat{\sigma}_{e j}^{2}$ is the estimated residual variance in lactation $j$ (note that for lactations $5-7$, the same residual variance was assumed).

The genetic correlations between lactations were estimated as

$$
\hat{\rho}_{g}\left(j, j^{\prime}\right)=\frac{\hat{\sigma}_{a}\left(j, j^{\prime}\right)}{\sqrt{\hat{\sigma}_{a}^{2}(j) \times \hat{\sigma}_{a}^{2}\left(j^{\prime}\right)}} .
$$

\section{RESULTS}

A summary of statistics of the reproductive and productive variables involved in this study is shown in Table 1. All fertility traits showed a slight trend to deteriorate from first to second lactation. A plateau was observed from the second to the fourth lactation, when fertility seemed to improve, except for DFS, which showed a steady increase across lactations. Nev-

\begin{tabular}{|c|c|c|c|c|c|c|c|}
\hline Item $^{1}$ & \multicolumn{7}{|c|}{ Parity number } \\
\hline $\mathrm{AC}(\mathrm{mo})$ & $27.1(3.4)$ & $40.7(4.3)$ & $53.9(5.1)$ & $67.1(5.8)$ & $79.7(6.4)$ & $92.4(6.9)$ & $104.9(7.2)$ \\
\hline $\operatorname{DFS}(\mathrm{d})$ & $83.1(29)$ & $84.1(29)$ & $84.3(29)$ & $85.0(29)$ & $85.1(29)$ & $85.2(29)$ & $85.8(29)$ \\
\hline DO (d) & $122.3(65)$ & $128.4(66)$ & $128.2(65)$ & $128.6(64)$ & $127.9(64)$ & $127.3(63)$ & $125.6(61)$ \\
\hline
\end{tabular}
ertheless, deterioration of fertility across lactations was small, on average, roughly $2 \mathrm{~d}$ for DFS, $6 \mathrm{~d}$ for DO, $4 \%$ in NRFS, and 0.14 inseminations for NSC.

Table 2 shows the value of the $\log$-likelihood $(\log \mathbf{L})$ of the data for models differing in the polynomial

Table 1. Number of observations used in the study and summary statistics (average and SD in parentheses) for production and fertility traits in the first 7 parities

${ }^{1} \mathrm{FP}$ : average fat plus protein yield in the closest 2 test days to the date of first insemination; AC: age at calving; DFS: interval from calving to first service; DO: days open; NRFS: nonreturn rate in the first service; NSC: number of services per conception. 
Table 2. Logarithm of the restricted likelihood and number of parameters (NP) for differing degrees of the random regression polynomial (Pol.) adjusted to the additive genetic values for models, adjusting (Ad) or not adjusting (unAd) for fat and protein yield in the closest test days to AI

\begin{tabular}{|c|c|c|c|c|c|c|c|c|c|}
\hline \multirow[b]{2}{*}{ Pol. degree } & \multirow[b]{2}{*}{ NP } & \multicolumn{2}{|c|}{$\mathrm{DFS}^{1}$} & \multicolumn{2}{|c|}{$\mathrm{DO}^{2}$} & \multicolumn{2}{|c|}{$\mathrm{NRFS}^{3}$} & \multicolumn{2}{|c|}{$\mathrm{NSC}^{4}$} \\
\hline & & unAd & Ad & unAd & $\mathrm{Ad}$ & unAd & $\mathrm{Ad}$ & unAd & $\mathrm{Ad}$ \\
\hline 0 & 8 & $-5,256$ & $-7,426$ & $-7,080$ & $-7,211$ & 5,060 & 4,740 & $-6,875$ & $-7,743$ \\
\hline 1 & 10 & $-5,162$ & $-7,396$ & $-6,987$ & $-7,114$ & 5,102 & 4,800 & $-6,716$ & $-7,548$ \\
\hline 2 & 13 & $-5,111$ & $-7,380$ & $-6,947$ & $-7,073$ & 5,119 & 4,824 & $-6,693$ & $-7,507$ \\
\hline
\end{tabular}

degree fitted to the additive genetic effect and in the adjustment or not for FP production level. Note that in the table $\log \mathrm{L}$ was obtained from the REML likelihood provided by ASReml. Because the REML likelihood only depends on variances, model comparisons can only be done with respect to random effects, in this case, the varying polynomial degree fitted to additive genetic effects. Thus, comparison of the $\log \mathrm{L}$ statistic between the 2 models differing in the adjustment for FP production level is not valid. A Wald test resulted in a significant effect $(P<0.001)$ of $\mathrm{FP}$ on fertility in all models. For all traits and type of FP adjustment, a second degree polynomial showed the best fit. Other model comparison criteria, such as the Akaike information criterion and Bayesian information criterion (not shown), provided the same ranking of models.

Estimated heritability in each parity for FPAd and FPUnAd models are shown in Figure 1. For all traits, heritability estimates increased from the first to the fourth lactation and decreased afterward. Estimates for all traits, models, and parities were within the range of 0.03 to 0.10 . Taking into account the standard error of the heritability estimates (ranging between 0.002-0.003), the only trait showing significant differences between FPAd and FPUnAd models was DFS. For this trait, larger values of heritability estimates were found for the FPAd model (0.10 vs. 0.08 for FPAd and FPUnAd, respectively, in lactation 4). For other traits, differences in heritability estimates were much smaller, ranging from $<0.0005$ for DO in lactation 7 to 0.01 for NSC in lactation 4. For traits other than DFS, heritability estimates from FPUnAd models tended to be larger than estimates from FPAd models.

The permanent environmental and herd variances (data not shown) ranged between 4 and $6 \%$ of the total phenotypic variance. Despite the small heritability estimates obtained, EBV displayed substantial variability. Figure 2 shows the distribution of EBV from FPAd models for the 4 reproductive traits for 900 sires with more than 50 daughters for the first lactation. Differ- ences in EBV for the best and worst sires were $30 \mathrm{~d}$ for DFS, 1.04 services for NSC, $0.61 \%$ for NRFS, and 56 $\mathrm{d}$ for DO for FP adjusted data. Apart from variability in the level of reproductive response, variability in the shape of response along lactations was also observed.

Contour plots of the estimated genetic correlations $\left(\mathbf{r}_{\mathrm{g}}\right)$ between lactations are shown in Figure 3 for the FPAd model. The correlations between adjacent lactations showed values larger than $r_{g}>0.90$ for all traits and close to $r_{g}=0.99$ for the fourth and fifth lactations. Estimated correlations between the most distant parities (first and seventh) ranged between $r_{\mathrm{g}}=0.36$ (for DFS) and 0.63 (for DO). The FP adjustment (results not shown) did not greatly affect the estimates of genetic correlations. Again, DFS was the trait with the

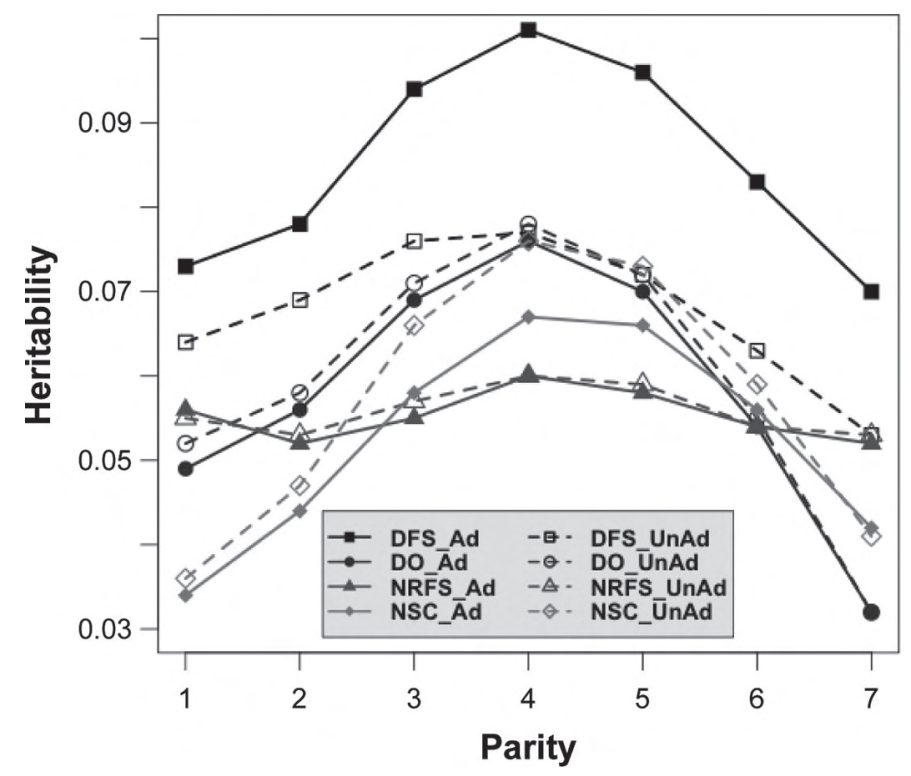

Figure 1. Heritability estimates obtained using models that adjust (Ad) or do not adjust (UnAd) for fat and protein production for days to first service (DFS), days open (DO), nonreturn rate for first service (NRFS), and number of services per conception (NSC). Standard errors of estimates ranged in the interval 0.002 to 0.003 
DFS

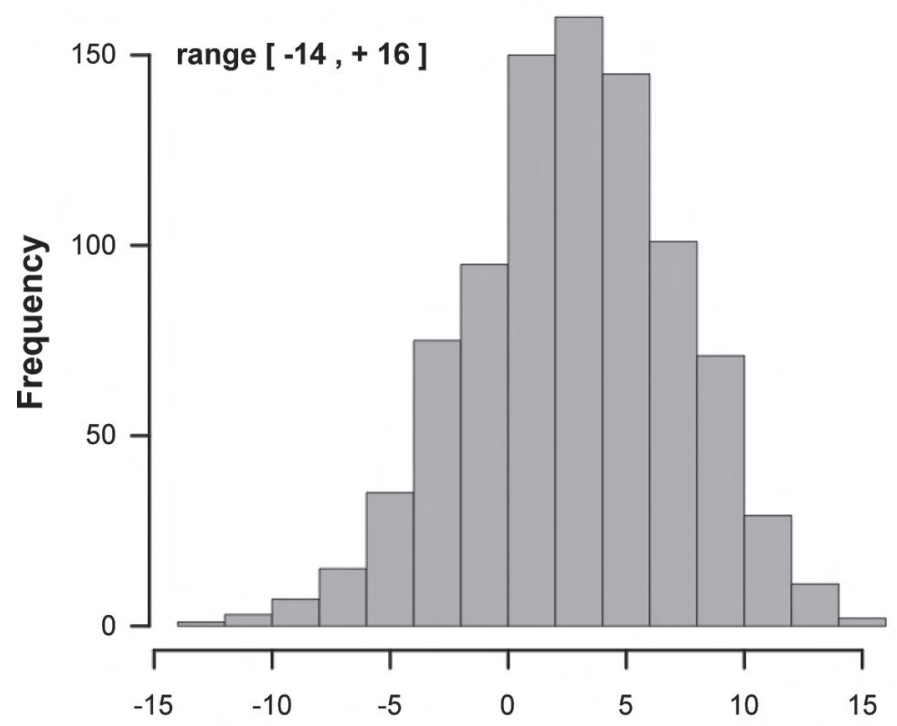

NRFS

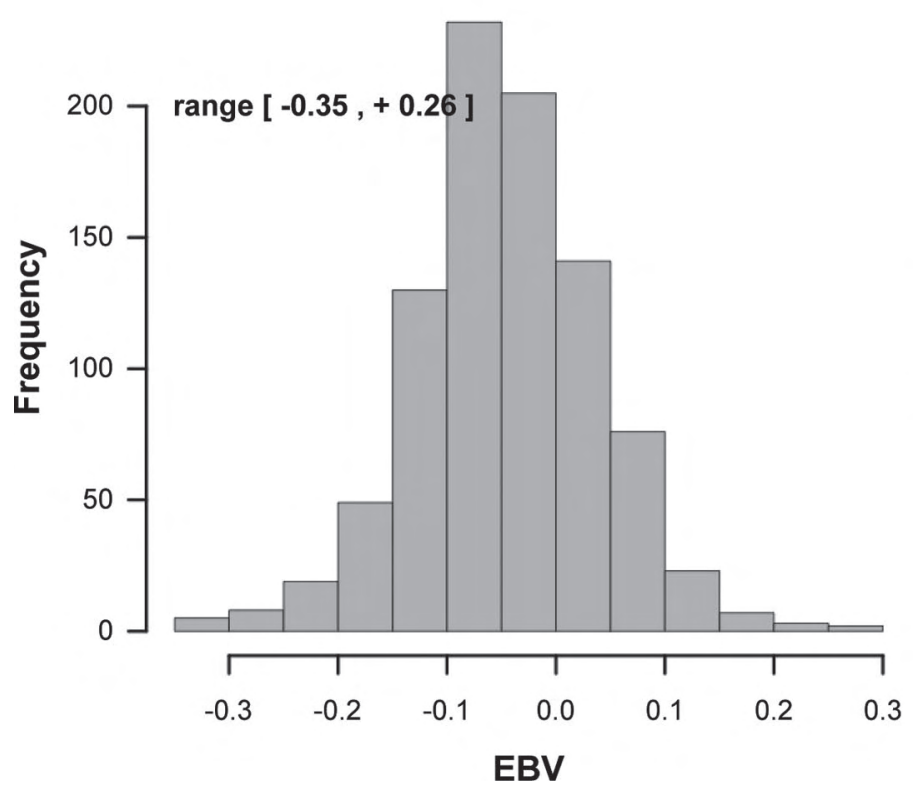

DO

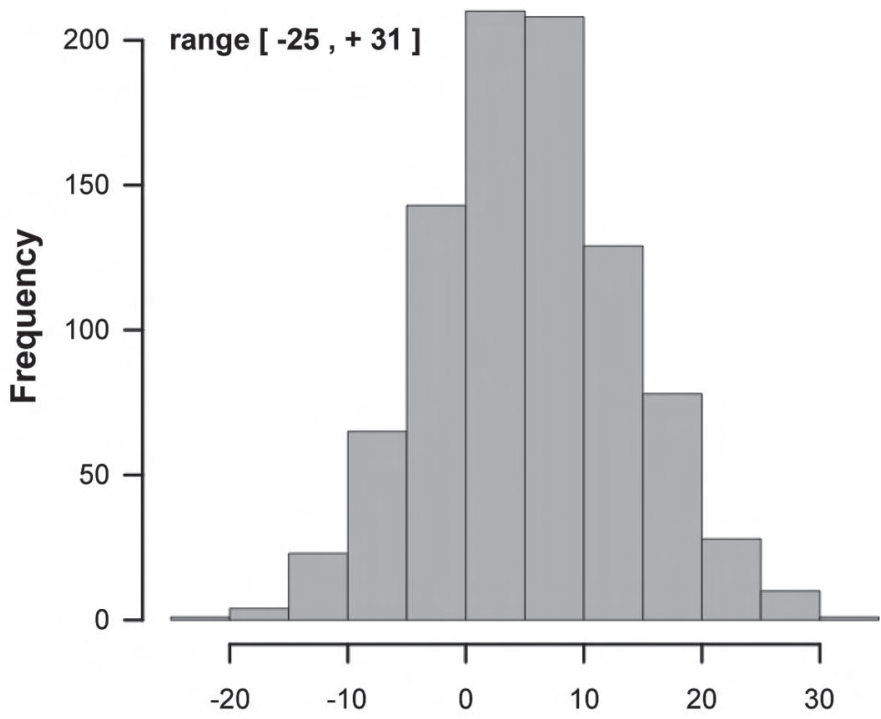

NSC

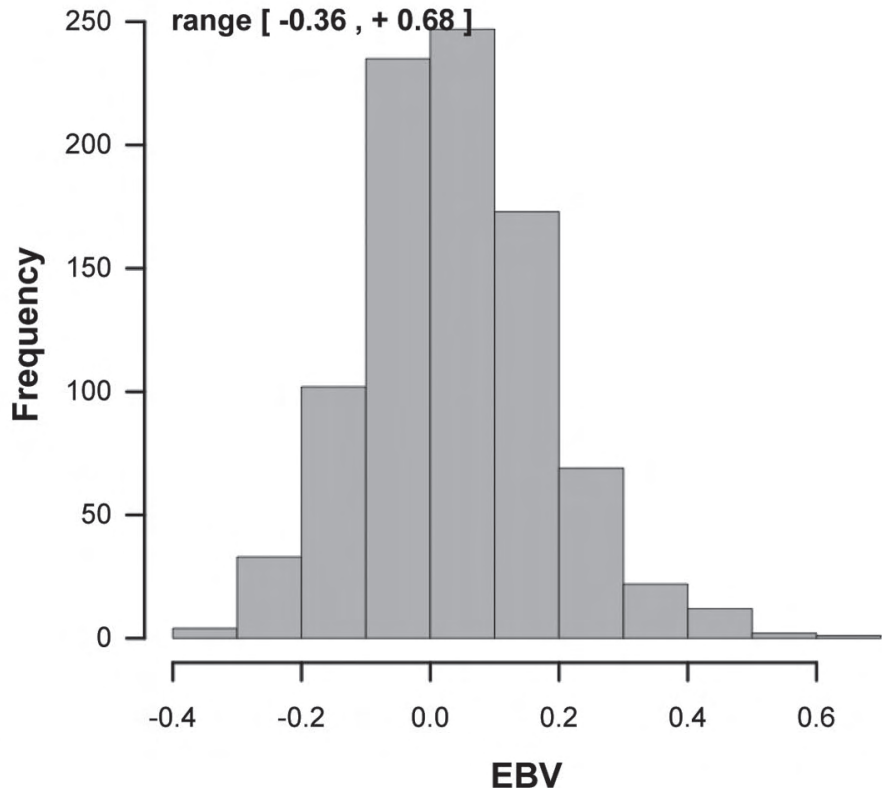

Figure 2. Observed distribution of EBV in first lactation of sires with more than 50 daughters days to first service (DFS), days open (DO), nonreturn rate for first service (NRFS), and number of services per conception (NSC) using the model that adjusts for fat and protein production.

largest differences in estimated genetic covariances and correlations between parities. The largest difference in estimates was found for the correlation between first and third lactation, showing values of $\mathrm{r}_{\mathrm{g}}=0.76$ and 0.87 for the FPAd and FPUnAd models, respectively.

The estimated genetic correlation matrix from the second degree polynomial model was factored into its corresponding eigenvector and eigenvalue matrices (Table 3) to determine the possibility of a decompos- ing level and persistency of reproduction along time, similar to that which has been done for production traits in dairy cattle (Olori et al., 1999, Macciotta et al., 2004, Togashi and Lin, 2006). The first eigenvalue explained between 82 and $92 \%$ and the second between 8 and $14 \%$ of the genetic variability in shape patterns in reaction of fertility across lactations. For all traits, the corresponding first eigenvector coefficients (Figure 4) showed a close-to-flat pattern and the second showed 

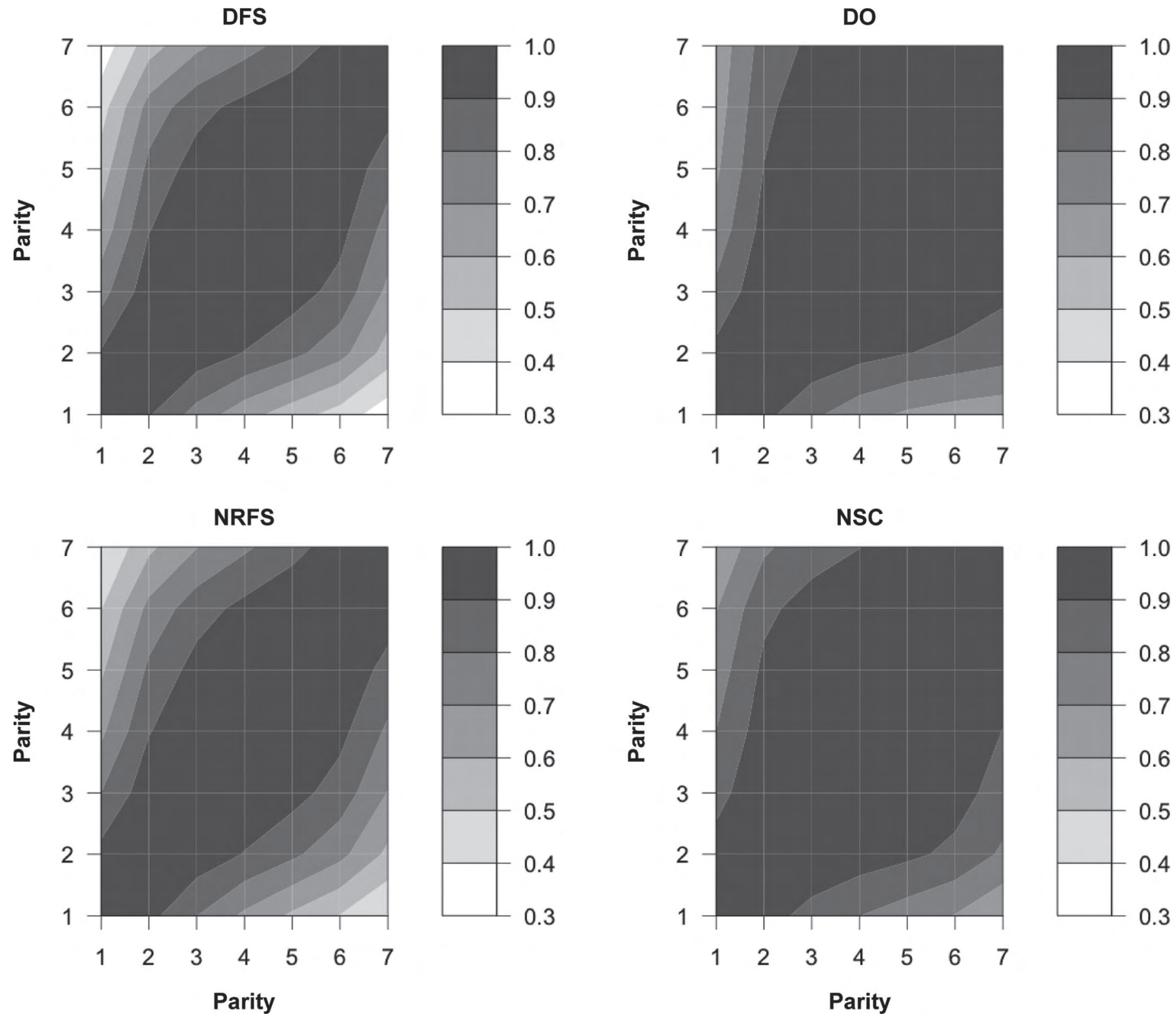

Figure 3. Contour plots of the estimated correlation matrices between pairs of lactations for fertility traits. DFS $=$ days from calving to first service; DO = days open; NRFS = nonreturn rate for first service; NSC = number of services per conception .

a linear trend. Alternatively, the eigen decomposition of the matrix of (co)variances of the random regression coefficients was also explored (results not shown). The first, second, and third eigenvectors revealed a close correspondence with the intercept, linear, and quadratic random regression coefficients (data not shown), respectively. The percentage of the total variability explained by each eigencomponent and the eigenfunction patterns were very close to the ones obtained with the matrix of correlations between parities and will be not shown.
To show the variability in the form of response across parities, the best 50 sires (with at least 150 daughters) for each trait were selected according to EBV at first calving. In practical terms, this is the first information available in a breeding program; accordingly, any of these sires can be selected as parents of the next generation. However, if the results from RRM are used to estimate the EBV of the same elite sires across successive calvings, a new and valuable genetic variability emerges: the ability to sustain reproductive performance across parities, as shown in Figure 5. For all traits, 
Table 3. Percentage of variability explained by the first 2 eigenvalues of the correlation matrix of additive genetic random regression model for second degree polynomial models adjusting for fat and protein yield in the closest test day to AI

\begin{tabular}{lrrrr}
\hline Eigenvalue & $\mathrm{DFS}^{1}$ & $\mathrm{DO}^{2}$ & $\mathrm{NRFS}^{3}$ & $\mathrm{NSC}^{4}$ \\
\hline First & 82.6 & 91.8 & 83.6 & 90.9 \\
Second & 14.1 & 7.8 & 13.5 & 7.8 \\
\hline
\end{tabular}

${ }^{1}$ DFS: interval from calving to first service.

${ }^{2}$ DO: days open.

${ }^{3}$ NRFS: nonreturn rate in the first service.

${ }^{4} \mathrm{NSC}$ : number of services per conception.
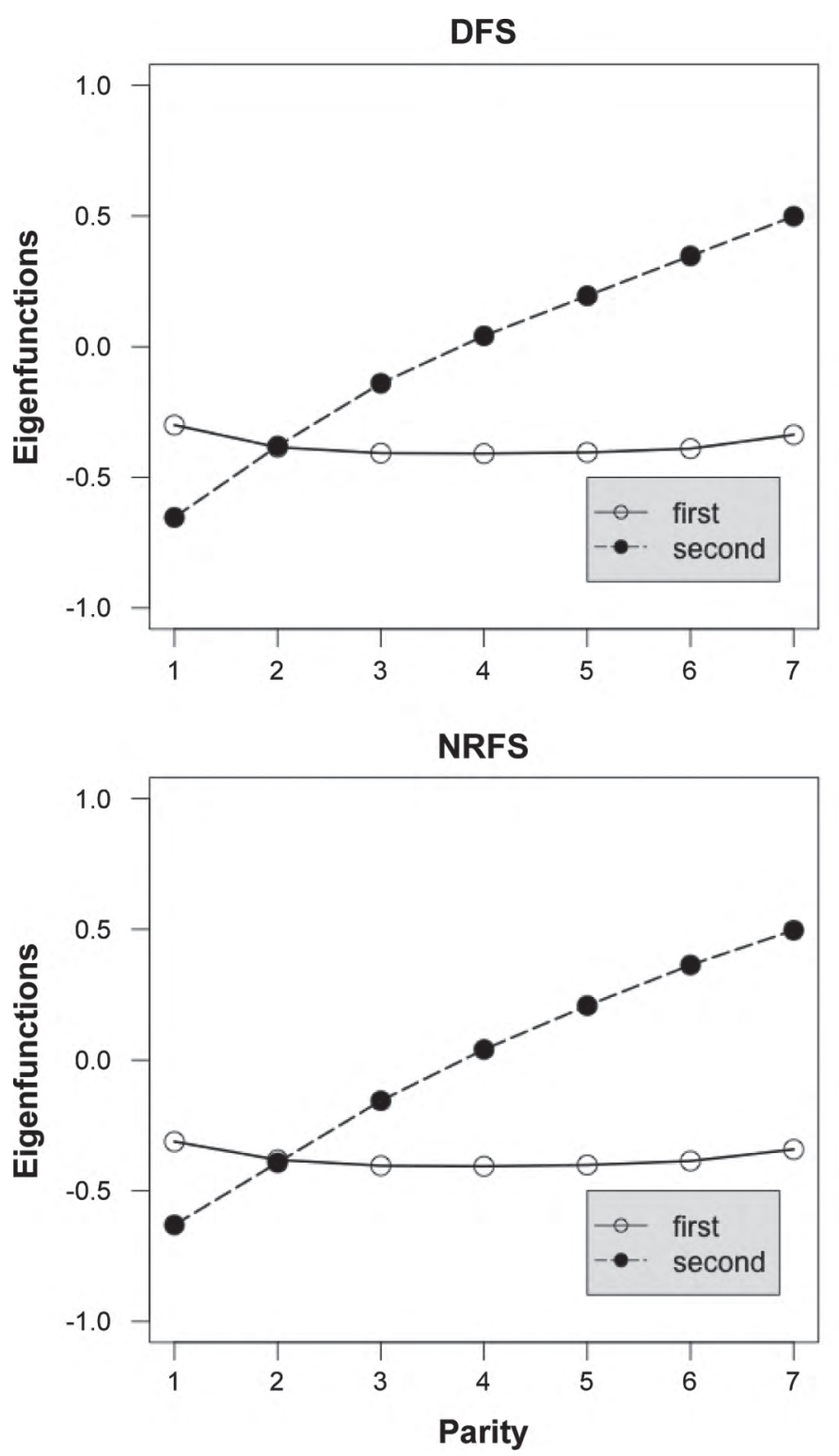

a substantial reranking and variation in the shape of response across lactations was observed. Nevertheless, the more important aspect to highlight is the difference between the EBV of the same sires in different calvings, a characteristic known as plasticity.

Estimated genetic trends in standard deviation units for reproductive traits in the first, fourth, and seventh parities are shown in Figure 6 for FPAd models. Trends for other lactations were suppressed to make the figure clearer. The estimated genetic potential for reproductive performance decreased along time for the cows in this population for all traits. This deterioration was much less evident for first parity fertility. Also, adjust-
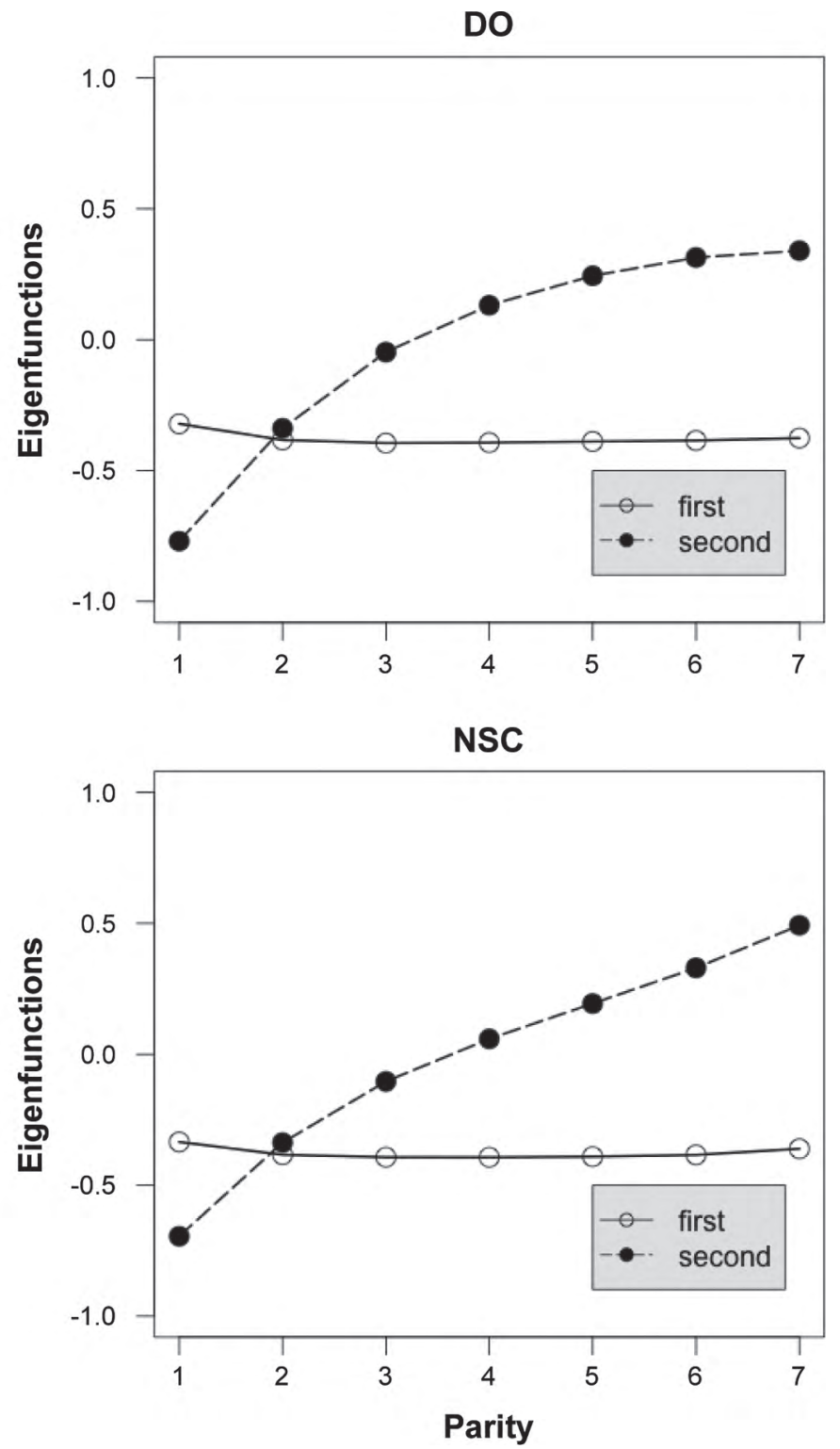

Figure 4. Eigenfunctions associated to the correlation matrix between additive genetic values at successive lactations for days to first service (DFS), days open (DO), nonreturn rate for first service (NRFS), and number of services per conception (NSC). 

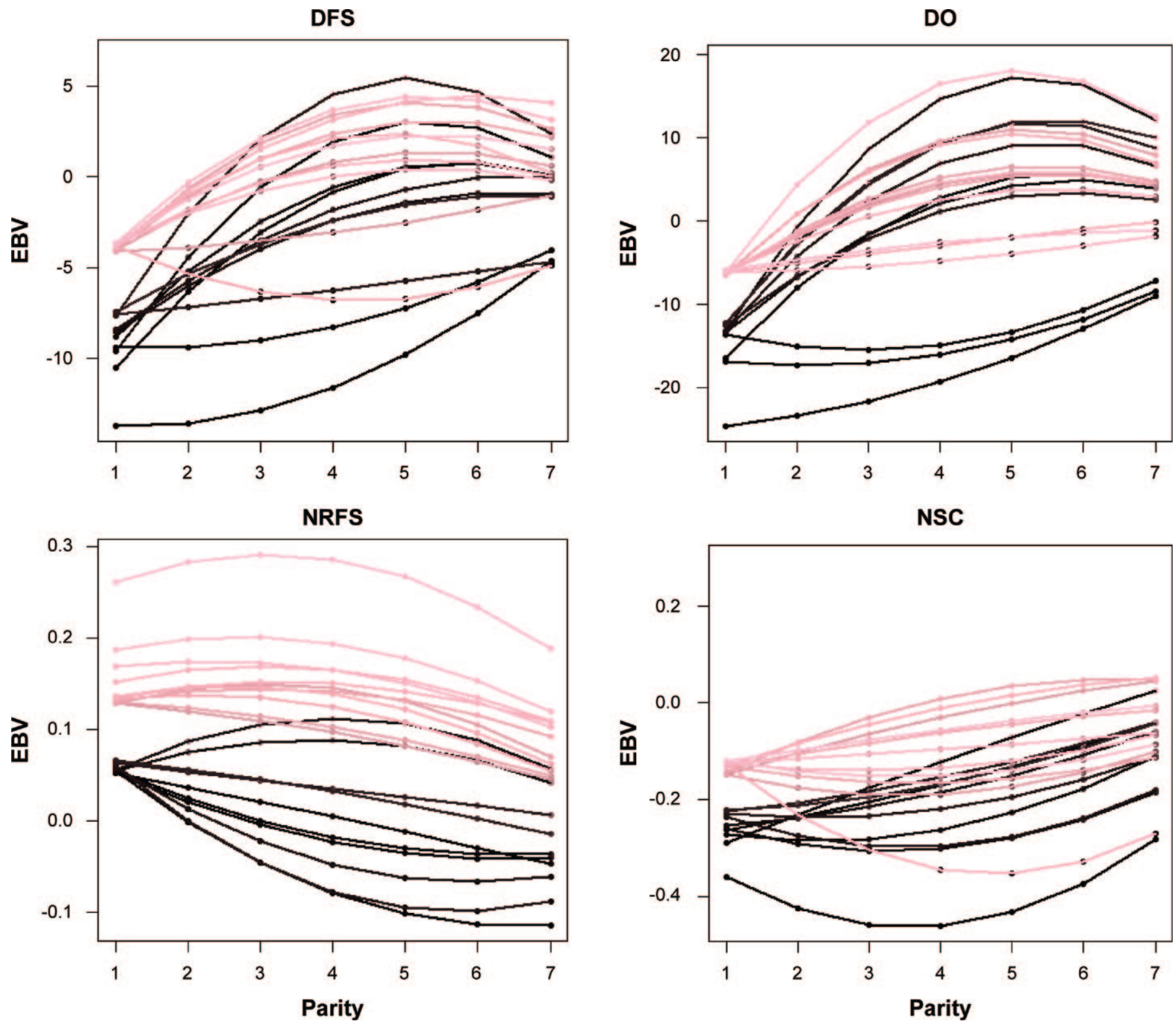

Figure 5. Estimated breeding values across parities for the top 50 sires with at least 150 daughters [only the top (in light color) and bottom (in dark color) 10 bulls out of the 50 are shown], selected on their EBV at first calving for days to first service (DFS), days open (DO), nonreturn rate for first service (NRFS), and number of services per conception (NSC) using the model that adjusts for fat and protein production. Color version available in the online PDF.

ment for FP had a negligible effect on the estimated trend for all fertility traits in this lactation, except for DFS. For later parities, DFS was the only trait for which a steeper trend was found when FP was included in the model to estimate EBV. In contrast, NSC and NRFS showed somehow shallower trends when FP was adjusted. The DFS, NRFS, and NSC showed a similar loss along the studied period of around 0.6 standard deviation units, whereas DO accumulated losses from DFS and NSC resulting in an increase (nonbeneficial) of 1 genetic standard deviation.
Figure 7 shows the estimated trend in genetic standard deviation units for the additive genetic regression coefficients for the 4 traits analyzed. The intercept, which represents the fertility level of the cow, and the quadratic coefficient, which defines the degree of concavity or convexity of curves of fertility traits across lactations, showed similar trends in magnitude but of opposite signs. The linear coefficient, which represents the trend of the reproductive performance to increase or decrease along lactations, showed flatter estimated genetic trends. The trend of intercepts along time was 

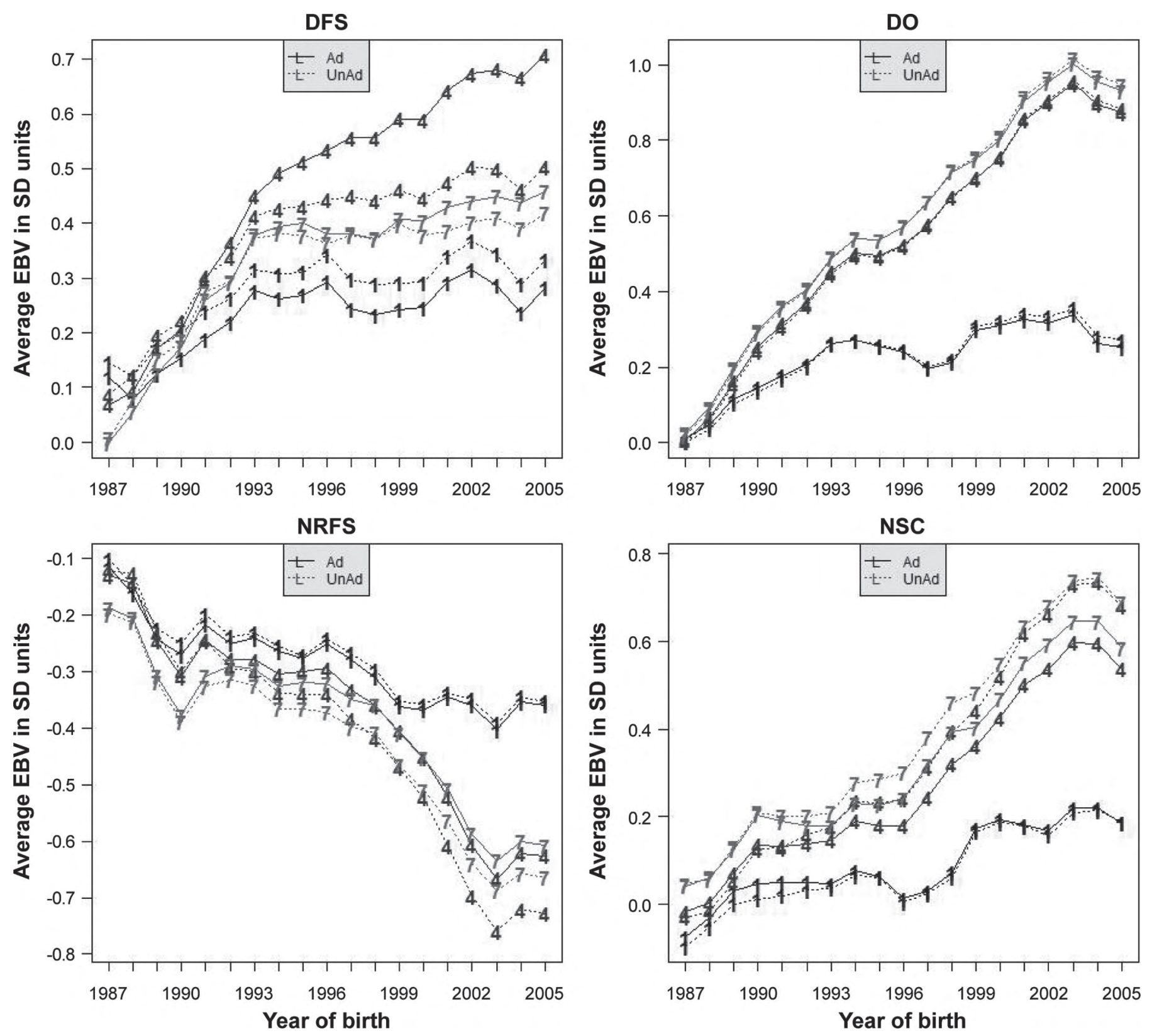

Figure 6. Genetic trends for reproductive traits estimated from changes in average EBV in standard deviation units along year of birth of the cows for days to first service (DFS), days open (DO), nonreturn rate for first service (NRFS), and number of services per conception (NSC) using the model adjusting (Ad) and not adjusting (UnAd) for fat and protein yield. Number of lactation (L) appears as point symbol in the genetic trends lines.

consistent with the deterioration of fertility traits presented in Figure 6, as might have been expected. Trends for the linear coefficient were steeper for DO and NSC, which indicates that cows born in more recent years tend to show sharper increases of both traits in later lactations. This agrees with the more marked deterioration of reproductive performance for later versus first parities, shown in Figure 6. Trends along time in the estimated quadratic coefficients indicate that cows born in more recent years show a more curvilinear response of the reproductive trait along lactations. Adjustment for FP resulted in markedly steeper trends for DFS (not shown), whereas flatter genetic trends for NRFS and NSC or no effect of the FP adjustment for DO were also observed.

\section{DISCUSSION}

Phenotypic records indicate that, except for DFS, fertility in successive lactations showed a slightly curvi- 
DFS

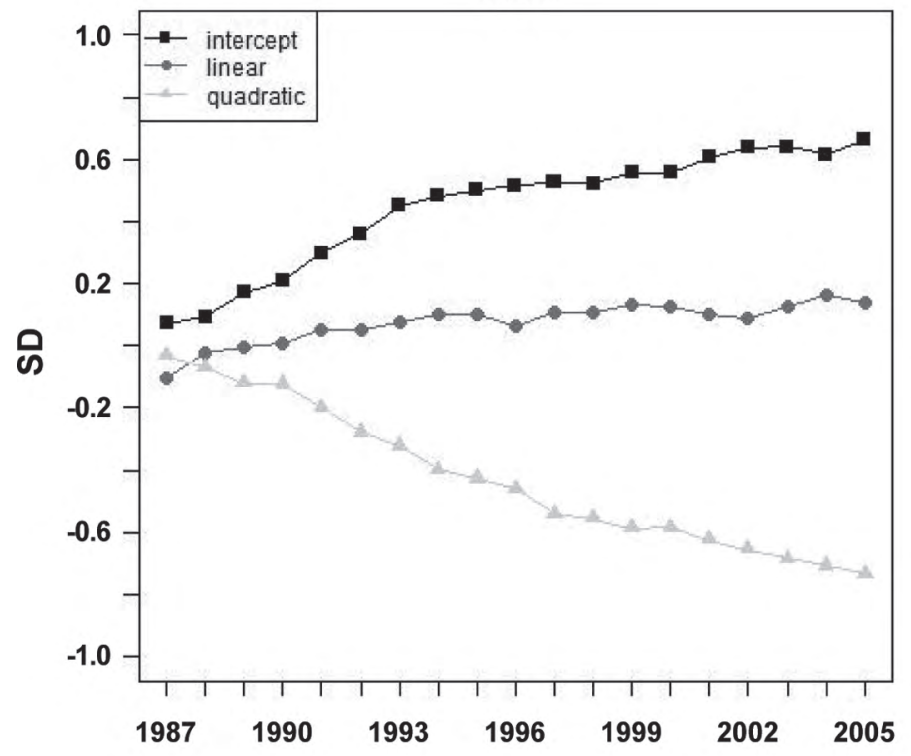

NRFS

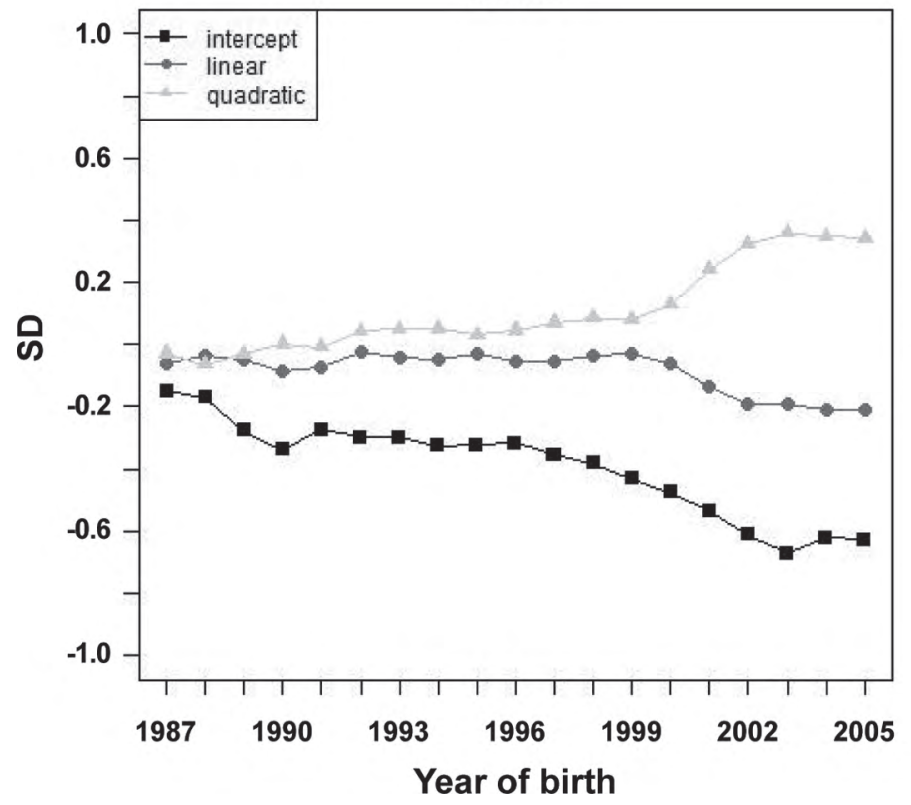

DO

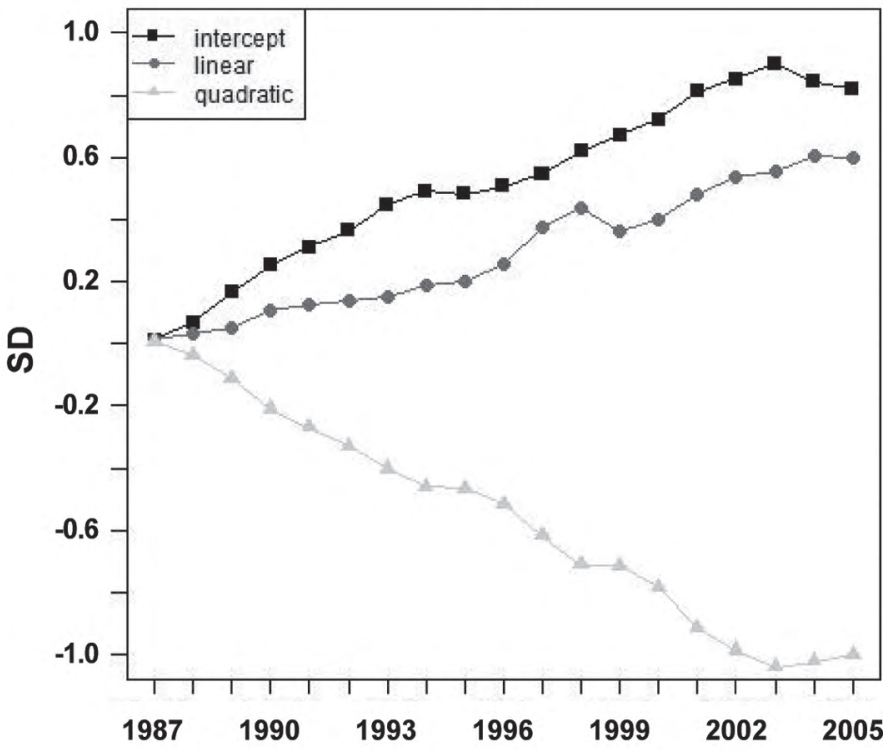

NSC

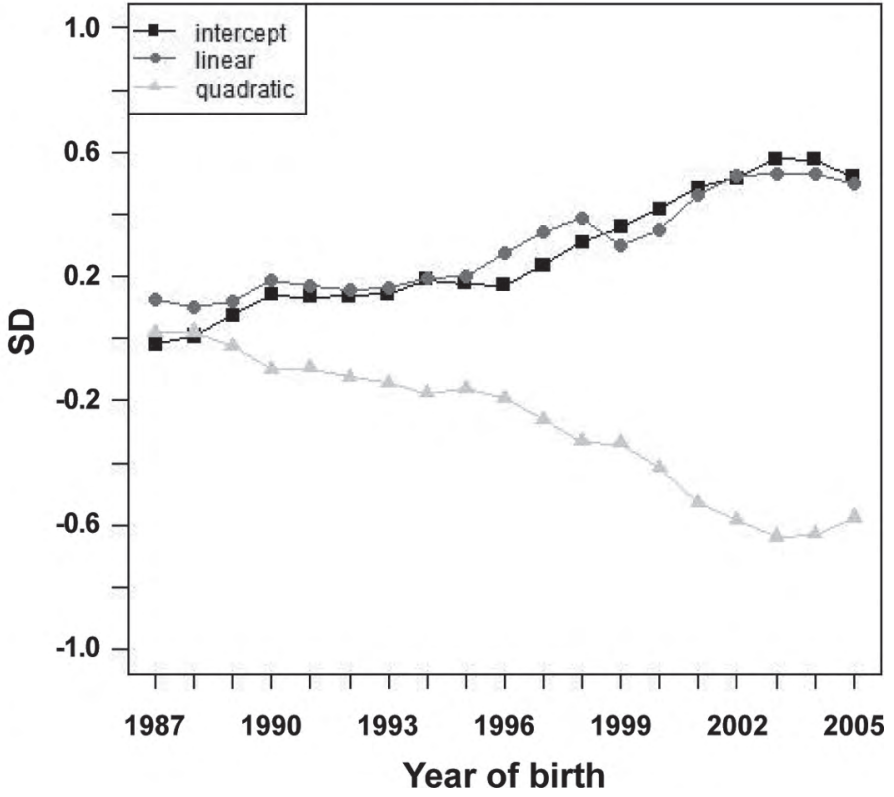

Figure 7. Estimated trends for standardized additive genetic random regression coefficients using the model that adjusts (Ad) for fat and protein yield for days to first service (DFS), days open (DO), nonreturn rate for first service (NRFS), and number of services per conception (NSC).

linear trend in this population, deteriorating from first to second and later lactations and then improving after the fourth lactation. A possible explanation for the unexpected improvement in late lactations might be the fact that cows with poor fertility were culled during the first lactations so only those with good fertility records survive to the fourth calving. Also, the interaction with milk yield might explain the observed reproductive performance across lactations. Fat plus protein yield increased from first to third lactation and decreased afterward. The antagonistic relationship between milk production and fertility might be causing the observed trend. This antagonism has been linked to the resource allocation theory, recently reviewed in Rauw (2008), which postulates that animals highly selected for milk yield dedicate resources (either from feed or from body 
reserves) primarily to the trait they were selected for, inducing a negative energy balance. Accounting for milk yield when analyzing fertility should therefore help in identifying animals with good potential for reproduction, which they do not show because of high milk yields. In our study, including FP as a covariate in the models for fertility traits had variable results for the different traits. A noticeable effect of the FP adjustment was observed in the estimated genetic trends for DFS, which showed a steeper trend when FP was included in the model of analysis. The larger effect of milk production level on DFS than on the other traits might be due to the fact that DFS is determined by both the genetic potential of a cow to commence luteal activity after calving and by management decisions about the date of first insemination, which might be based on the production level of the cow. Contrary to DFS, genetic trends for NSC and NRFS were flatter when FP was included in the models of analysis, although differences were smaller than in the case of DFS. In previous studies where fertility and production traits have been analyzed in multi-trait settings, a tendency to find larger variability of EBV and steeper trends when compared with single trait analyses for fertility has been observed (Olori et al., 2002; Kadarmideen et al., 2003; Sewalem et al., 2010; Sun et al., 2010). In the present study, the relatively small effect of the phenotypic correction in most of the analyzed traits might be explained by the fact that adjustment by phenotypic FP production does not account for selection and culling based on the genetic potential of cows for production and does not rely on the stronger genetic correlations between production and fertility, compared with the phenotypic correlations.

As in previous studies (Norman et al., 2007; Weigel, 2006), heritability estimates of reproductive traits were below $10 \%$, but variability among sires was substantial. Genetic correlations across lactations were large between adjacent lactations but differed from one for more distant parities; the same trends were presented by Jamrozik et al., (2005) and Liu et al., (2008). Therefore, animals could rank differently depending on lactation number, which might result in bias in genetic evaluations if repeatability models are used. The reranking of sires across lactations represents a type of genotypeenvironment interaction, which can be quantified by reaction norm models (de Jong and Bijma, 2002) similar to those used in this study. This statistical approach allows an estimate of the variability among sires in the pattern of additive genetic breeding values along the trajectory of successive calvings. Sires showing increasing or decreasing trends along parities will produce daughters that will increase or decrease the value of the trait with respect to the average phenotypic pattern of reproductive performance along lactations. Sires that maintain or improve reproductive performance along parities would be selection candidates. This characteristic is known as plasticity (de Jong and Bijma, 2002), which can be considered as a new tool for selection of fertility traits in dairy cattle, compared with the current criteria of overall reproductive ability, and should favor more robust cows in the sense of maintenance of fertility levels along the whole productive life. In this study, the difference between EBV at third calving minus EBV at first calving for the 900 bulls in Figure 2 ranged between -12 and $+16 \mathrm{~d}$ for DFS, -0.20 and +0.48 for NSC, -8 and +27 for DO, and -0.17 and +0.12 for NRFS. Compared with the results presented in Figure 2, which represents EBV variability within first lactation ( -14 to +16 DFS, 0.36 to $+0.68 \mathrm{NSC}$, -25 to $+31 \mathrm{DO}$, and -0.35 to $+0.26 \mathrm{NRFS}$ ), the magnitude of the variability of fertility across parities is a non-negligible source of genetic variation that can be used in breeding programs.

Most of the genetic variability observed in the shape of fertility performance along lactations was associated with the first eigenvalue of the correlation matrix. The corresponding eigenfunction showed a nearly constant level of reproductive performance through productive life. Therefore, fertility mean is expected to increase or decrease in a constant amount across lactations from selection for this first eigenfunction. Given that reproductive performance tends to decay with the number of lactations (at least up to a certain lactation), it is also important to provide selection criteria that avoid such deterioration. The associated eigenfunction from the second eigenvalue could be used for that purpose; nevertheless, selection for this component of reproductive performance would be expected to be less efficient than selection for the level of the trait because of the much smaller percentage of the total observed variability attached to the second eigenvalue. To our knowledge, the study of Nishida et al. (2006) is the only one using RRM to describe changes in reproductive performance across lactations in cattle. In their research, only the number of inseminations per conception was studied. Those authors found that the first eigenfunction represented a constant level of reproductive performance up to the sixth parity, increasing afterward. The second eigenfunction was similar to the one found in the current study. The fact that they used a smaller set of data from only one herd might explain the differences in the observed pattern for the first eigenfunction.

Results from the estimated genetic correlations indicate that the fertility level at different stages of the productive life of a cow is likely to be governed by a common group of genes (because of the non-null genetic correlations across lactations). Conversely, the eigen 
ecomposition of the corresponding genetic correlation matrix indicate that a different group of genes might control the rate of decay of fertility because of the fact that the first 2 eigenfunctions, associated with the level and change in fertility across lactations, represent 2 independent variables (because the eigen decomposition provides linearly independent eigenvectors). This would imply that selection of the right genotypes associated to those 2 groups of genes would result in more persistently fertile cows.

This study has confirmed the decay in estimated genetic potential for fertility along the last 2 decades in accordance with the worldwide concern for declining fertility in Holstein cows (Sørensen et al., 2007; Berglund, 2008). This is likely to be due to a correlated response from intense selection for production in the Holstein breed. In the current study, a step forward has been given by decomposing the overall estimated genetic trend for the traits in components related to the reproductive pattern across lactations, or in other words in the ability of cows not only to show a certain level of reproductive performance, but also to maintain it. The estimated response for the intercept coefficient indicated a decline in the level of fertility traits, agreeing with overall trends for traits per lactation. Moreover, a detrimental trend was found for the linear regression coefficient for DFS, DO, and NSC, which indicates a loss of the genetic ability to react to the cumulative stress load that is likely to occur when the number of parities increases. This trend was more pronounced for DFS, the cyclicity indicator.

\section{CONCLUSIONS}

Genetic deterioration of fertility continues to occur in dairy populations highly selected for milk production. In this study, accounting for milk production when analyzing fertility traits did not show a large effect on the EBV or in the estimated genetic trends; except for DFS, for which phenotypic level of milk production may be influencing the date of first service through management decisions. The existence of heterogeneous genetic (co) variance components and EBV across lactations is one of the main results of this study. Although the proportion of variance for fertility with an increasing number of lactations was small, an important genetic variability was estimated for the shape of response across the trajectory of calving number. The use of random regression models to analyze information on fertility traits along lactations can therefore provide new tools to take advantage of this variability to improve durability of cows, and help in improving sustainability of intensive milk production systems. Coefficients of eigenvectors of the matrix of correlations of fertility performance between pairs of lactations (or alternatively for the covariance or correlation matrix of the random regression coefficients) can be used to obtain new variables that will allow selection for overall level of fertility and for animals' plasticity along their productive life, retaining those able to maintain or improve their reproductive level after the first parity.

\section{ACKNOWLEDGMENTS}

This study was financed by the project INIA-FEDER: RTA2007-0071. Alberto Menéndez-Buxadera was partially supported by a grant from Universidad Politécnica de Madrid. Roger I. Cue thanks McGill University (Montreal, Canada) for a sabbatical leave at INIA.

\section{REFERENCES}

Berglund, B. 2008. Genetic improvement of dairy cow reproductive performance. Reprod. Domest. Anim. 43(Suppl. 2):89-95.

Calus, M. P. L., and R. F. Veerkamp. 2003. Estimation of environmental sensitivity of genetic merit for milk production traits using a random regression model. J. Dairy Sci. 86:3756-3764.

de Jong, G. 1995. Phenotypic plasticity as a product of selection in a variable environment. Am. Nat. 145:493-512.

de Jong, G., and P. Bijma. 2002. Selection and phenotypic plasticity in evolutionary biology and animal breeding. Livest. Prod. Sci. 78:195-214.

Gilmour, A. R., B. J. Gogel, B. R. Cullis, and R. Thompson. 2009. ASReml User Guide Release 3.0. VSN International Ltd., Hemel Hempstead, UK.

Gomulkiewicz, R. M., and M. Kirkpatrick. 1992. Quantitative genetics and the evolution of reaction norms. Evolution 46:390-411.

González-Recio, O., M. A. Pérez-Cabal, and R. Alenda. 2004. Economic value of female fertility and its relationship with profit in Spanish dairy cattle. J. Dairy Sci. 87:3053-3061.

Interbull. 2012. National GES Information. Accessed Oct. 4, 2012. http://www-interbull.slu.se/national_ges_info2/framesida-ges. htm.

Jamrozik, J., J. Fatehi, G. J. Kistemaker, and L. R. Schaeffer. 2005. Estimates of genetic parameters for Canadian Holstein female reproduction traits. J. Dairy Sci. 88:2199-2208.

Jorjani, J. 2007. International genetic evaluation of female fertility traits in five major breeds. Interbull Bull. 37:144-147.

Kadarmideen, H. N., R. Thompson, M. P. Coffey, and M. A. Kossaibati. 2003. Genetic parameters and evaluations from single- and multiple-trait analysis of dairy cow fertility and milk production. Livest. Prod. Sci. 81:183-195.

Kirkpatrick, M., D. Lofsvold, and M. Bulmer. 1990. Analysis of the inheritance, selection and evolution of growth trajectories. Genetics 124:979-993.

Kolmodin, R., E. Strandberg, P. Madsen, J. Jensen, and H. Jorjani. 2002. Genotype by environment interaction in Nordic dairy cattle studied using reaction norms. Acta Agric. A Scand. Anim. Sci. $52: 11-24$.

Liu, Z., J. Jaitner, F. Reinhardt, E. Pasman, S. Rensing, and R. Reents. 2008. Genetic evaluation of fertility traits of dairy cattle using a multiple-trait animal model. J. Dairy Sci. 91:4333-4343.

Macciotta, N. P. P., D. Vicario, C. D. Mauro, and A. Cappio-Borlina. 2004. A multivariate approach to modeling shapes of individual lactation curves in cattle. J. Dairy Sci. 87:1092-1098.

Miglior, F., B. L. Muir, and B. J. Van Doormaal. 2005. Selection indices in Holstein cattle of various countries. J. Dairy Sci. 88:12551263.

Nishida, A., M. A. Aziz, S. Nishida, and K. Suzuki. 2006. Modeling number of services per conception of Japanese Black cattle by random regression. J. Anim. Breed. Genet. 123:56-63. 
Norman, H. D., J. R. Wright, S. M. Hubbard, M. T. Kuhn, and R. H. Miller. 2007. Genetic selection for reproduction: Current reproductive status of the national herd. Pages 69-78 in Appl. Sel. Indexes Dairy Prod. Dairy Cattle Reprod. Conf., Denver, CO.

Olori, V. E., W. G. Hill, B. J. McGuirk, and S. Brotherstone. 1999 Estimating variance components for test-day milk records by restricted maximum likelihood with a random regression animal model. Livest. Prod. Sci. 61:53-63.

Olori, V. E., T. H. E. Meuwissen, and R. F. Veerkamp. 2002. Calving interval and survival breeding values as measure of cow fertility in a pasture-based production system with seasonal calving. J. Dairy Sci. 85:689-696.

Pletcher, S. D., and C. J. Geyer. 1999. The genetic analysis of agedependent traits: Modeling the character process. Genetics 153:825-835.

Rauw, W. M. 2008. Resource Allocation Theory Applied to Farm Animal Production. CAB International.

Schaeffer, L. R. 2004. Application of random regression models in animal breeding. Livest. Prod. Sci. 86:35-45.

Schaeffer, L. R., and J. C. M. Dekkers. 1994. Random regressions in animal models for test-day production in dairy cattle. Pages 443-446 in Proc. Fifth World Congr. Genet. Appl. Livest. Prod., vol. XVIII, Guelph, Canada.

Sewalem, A., J. Kistemaker, and F. Miglior. 2010. Relationship between female fertility and production traits in Canadian Holsteins. J. Dairy Sci. 93:4427-4434.
Shook, G. E. 2006. Major advances in determining appropriate selection goals. J. Dairy Sci. 89:1349-1361.

Sørensen, A. C., T. Lawlor, and F. Ruiz. 2007: A survey on fertility in the Holstein populations of the world. Page 17 in Proc. Fertil. Dairy Cows-Bridg. Gaps. August 30-31, 2007. Liverpool Hope University, Liverpool, UK.

Sun, C., P. Madsen, M. S. Lund, Y. Zhang, U. S. Nielsen, and G. Su. 2010. Improvement in genetic evaluation of female fertility in dairy cattle using multiple-trait models including milk production traits. J. Anim. Sci. 88:871-878.

Togashi, K., and C. Y. Lin. 2006. Selection for milk production and persistency using eigenvectors of the random regression coefficient matrix. J. Dairy Sci. 89:4866-4873.

VanRaden, P. M. 2003. Genetic evaluations for fitness and fertility in the United States and other nations. Pages 103-106 in Proc. Natl. Dairy Genetics Workshop, Raleigh, NC. Virginia Polytechnic Inst. State Univ., Blacksburg.

Veerkamp, R. F., J. J. Windig, M. P. L. Calus, W. Ouweltjes, Y. De Haas, and B. Beerda. 2008. Selection for high production in dairy cattle. Pages 243-260 in Resource Allocation Theory Applied to Farm Animal Production. W. M. Rauw, ed. CAB International, Oxfordshire, UK.

Weigel, K. A. 2006. Prospects for improving reproductive performance through genetic selection. Anim. Reprod. Sci. 96:323-330. 